\title{
Effect of maternal active smoking during pregnancy on the trajectory of childhood body mass index: A multilevel analysis using quartiles of birthweight
}

\author{
Miho Kamiya ${ }^{1,2}$, Kohta Suzuki', Zentaro Yamagata ${ }^{3}$
}

\begin{abstract}
INTRODUCTION Maternal active smoking during pregnancy is associated with childhood obesity; however, whether maternal active smoking affects childhood body mass index (BMI) according to birthweight has not been examined.

METHODS The study participants were 1955 women and their single-born infants, born between 1 April 1991 and 31 March 2003, in Koshu City, Japan, for whom complete data for birthweight, pre-pregnancy maternal BMI and pregnancy smoking status were available. Maternal smoking status during pregnancy was recorded using a questionnaire at the time of pregnancy registration. Childhood BMI was estimated by the BMI z-score, established by the World Health Organisation. Birthweight quartiles were grouped by sex and parity (first vs second or higher). Multilevel analysis, including both the individual and time as different level variables by each birthweight quartile, was used to describe the trajectories of BMI z-scores for statistical analyses.

RESULTS In every quartile group, although children born to smoking mothers were leaner at birth, their BMI z-score increased around the age of 3 years. These children were larger than children born to non-smoking mothers. Significant interactions between maternal active smoking during pregnancy and child's age were seen in those in the first and second quartiles of birthweight. Moreover, rapid growth in infancy was observed in the second quartile of birthweight. CONCLUSIONS The effect of maternal active smoking during pregnancy on childhood growth was more apparent among children in the second quartile of birthweight.
\end{abstract}

https://doi.org/10.18332/tid/119117

\section{INTRODUCTION}

In recent years, the 'Developmental Origins of Health and Diseases' (DOHaD) hypothesis, along with the established 'foetal programming' and 'Barker's hypothesis', have been employed to explain the mechanisms of childhood body mass index (BMI, kg/ $\mathrm{m}^{2}$ ) and development ${ }^{1}$. These hypotheses describe the association between a specific growth path, such as slow foetal growth and subsequent rapid infant

\section{AFFILIATION}

1 Department of Health and Psychosocial Medicine, Aichi Medical University School of Medicine, Nagakute, Japan 2 Department of Child and Family Health Nursing, Faculty of Nursing, Japanese Red Cross College of Nursing Shibuya, Japan

3 Department of Health Sciences, Graduate School of Medicine, University of Yamanashi, Chuo, Japan

\section{CORRESPONDENCE TO}

Kohta Suzuki. Department of Health and Psychosocial Medicine, Aichi Medical University School of Medicine, 1-1 Yazakokarimata, Nagakute, Aichi 4801195, Japan. E-mail: kohtas@aichi-med-u.ac.jp ORCID ID: https://orcid. org/0000-0002-8151-6927

\section{KEYWORDS}

birthweight, pregnancy, active smoking, childhood growth, body mass index

Received: 14 November 2019 Revised: 28 January 2020 Accepted: 16 March 2020 
Hernández-Diaz et al. ${ }^{7}$ described infant mortality among smoking versus non-smoking mothers. Although infant mortality increased as birthweight decreased among infants in both groups, a 'birthweight paradox' was reported ${ }^{7}$, which suggested that the birthweight-specific mortality rate curve of infants born to smoking mothers crossed over that of infants born to non-smoking mothers at approximately 2000-2250 g. The authors explained this paradox by using directed acyclic graphs (DAGs) to consider causal models for the effects of unmeasured factors on birth weight and infant mortality ${ }^{7}$. Thus, it might be necessary to consider potential effects on birthweight from perinatal exposure to certain factors, such as maternal smoking, which impact on childhood health outcomes.

It has been suggested that maternal active smoking during pregnancy is a major factor affecting foetal and childhood $\mathrm{BMI}^{8-17}$. We have previously described this association using data from national (Japan Environmental and Children's Study, JECS) and community-based birth cohort studies in Japan (Project Koshu) ${ }^{18-24}$. We found that there were both direct and indirect correlations between maternal active smoking during pregnancy and rapid infant growth ${ }^{24}$. We speculated that breastfeeding and birthweight might be intermediate factors between maternal active smoking during pregnancy and rapid infant growth ${ }^{24}$. Furthermore, because reports suggest that rapid growth during infancy could be associated with subsequent obesity ${ }^{25-27}$, describing the trajectory of childhood BMI might be important in determining their future weight status.

Therefore, in addition to maternal active smoking, there might be other potential factors during pregnancy that are associated with birthweight and childhood BMI. Since these potential factors, which were impossible to measure, might be independent from maternal active smoking during pregnancy, the effect of the latter on childhood BMI might vary by birthweight. It is, therefore, necessary to describe the trajectory of childhood BMI stratified by birthweight.

It is also necessary to conduct individual growth analysis, including both the individual and age as different-level variables. Therefore, this multilevel analysis was appropriate for longitudinal data, which were obtained repeatedly at different time points.

Thus, this study aimed to examine differences in the effect of maternal active smoking during pregnancy on childhood growth based on trajectories of childhood BMI z-scores, using multilevel model analyses stratified by birthweight quartiles.

\section{METHODS}

\section{Study design and participants}

This study is part of Project Koshu (formerly Project Enzan), a dynamic, ongoing Japanese, communitybased, prospective cohort study that began in 1988. Details of this project have been described previously ${ }^{18-24}$. Participants were mothers who completed questionnaires during their pregnancy registration and whose infants were born between 1 April 1991 and 31 March 2003, in Koshu City, Japan. Koshu City has a population of 31000 , with approximately 150 births each year. Because the birthweight distribution significantly differs between multiple and singleton pregnancies, women with multiple pregnancies were excluded.

This study was approved by the ethical review board of the University of Yamanashi School of Medicine and was conducted in accordance with the Guidelines Concerning Epidemiological Research (Ministry of Education, Culture, Sports, Science, and Technology and Ministry of Health, Labour and Welfare, Japan), with cooperation from the Koshu City administration office. Participants provided written informed consent.

\section{Data collection}

Smoking status of pregnant women were recorded using a questionnaire during pregnancy registration. In Japan, maternal/child health laws require expectant mothers to register their pregnancies to access healthcare services. In the study area, almost all expectant mothers were registered by 18 weeks of gestation. Smoking status was categorised dichotomously; the 'smoking mother' category only included those participants who answered 'smoking', and the 'non-smoking mother' category included those who answered 'have quit smoking' or 'have never smoked' when asked about their smoking status.

Data regarding birth length and weight, birth order, and gestational week at delivery were obtained from the Maternal and Child Health Handbook, which is an official publication containing guidelines for obstetric professionals and pregnant women. Additionally, pregnant women used a booklet to record their 
health status during pregnancy. Childhood height and bodyweight data were collected via physical measurements taken during medical check-ups conducted when the children were 3 and 5 years old and when the children attended grades 2 and 4 of elementary school (i.e. ages $7-8$ and $9-10$ years, respectively). Height was measured using a stadiometer (unit: $0.1 \mathrm{~cm}$ ), and bodyweight was measured using conventional weighing scales (unit: $100 \mathrm{~g})$. BMI z-scores of children aged $0,3,5,7-8$, and 9-10 years, which were based on WHO standards, were used to adjust the differences in BMI for each month of age within the same age group ${ }^{28}$.

\section{Statistical analysis}

Based on birth order and sex, children were initially categorised into quartiles of birthweight. The individual growth analysis method (SAS PROC MIXED) was used to compare childhood BMI z-score trajectories between children born to smoking and non-smoking mothers in each quartile. We did not exclude participants for whom BMI z-score data were missing, as SAS PROC MIXED automatically handles missing data using maximum likelihood. This automatic imputation was a particular strength of this method compared with other statistical methods such as the generalised estimating equation. As our previous findings indicated nonlinearity in the slopes for BMI and BMI z-scores, adopting the approach used by Fitzmaurice et al. ${ }^{29}$, we used the following model to explore the differences in the slopes for each interval between the ages of measurement ${ }^{23}$ :

BMI z-score ${ }_{i t}=\beta_{1}+\beta_{2} \times$ Age $_{i t}+\beta_{3} \times$ Maternal smoking status $_{i}+\beta_{4} \times$ Age $_{i t} \times$ Maternal smoking status $_{i}$ $+\beta_{5} \times$ Maternal BMI before pregnancy ${ }_{i}+\mathrm{e}_{i t}$

where $i$ represents the individual, $t$ represents time, $\beta_{1-5}$ represent parameters, and $e$ is the error term. In the final models, years were used to form dummy variables for time. Sample clustering within individuals was addressed. In this analysis, individual BMI data recorded at birth and at least once after the children were 3 years old were used. Individual BMI z-scores, which were based on WHO standards, were used to adjust differences in BMI for each month of age within age groups ${ }^{28}$. We calculated BMI z-scores for each group at each age using the solution from the final model to describe the trajectories. For example, BMI z-scores for boys aged 3 years were calculated as follows:

BMI z-score at 3 years of age $=\operatorname{intercept}\left(\beta_{1}\right)+\beta_{2}$ at 3 years of age $+\beta_{3}$ of Smoking $(0$ or 1$)+\beta_{4}$ at 3 years of age and Smoking ( 0 or 1$)+\beta_{5} \times$ Maternal BMI before pregnancy $\left(\mathrm{kg} / \mathrm{m}^{2}\right)$.

All analyses were conducted using SAS version 9.4 (SAS Institute, Inc., Cary, NC, USA) statistical software.

\section{RESULTS}

The study participants were 1955 women and their single-born infants, for whom complete data for birthweight, maternal pre-pregnancy BMI, and smoking status during pregnancy were available. Birthweight and anthropometric data were collected from 1950 (at birth, 99.7\%), 1643 (at age 3 years, $84.0 \%$ ), 1517 (at age 5 years, 77.6\%), 1487 (at age 7-8 years, $76.1 \%$ ), and 1491 (at age $9-10$ years, $76.3 \%$ ) children. Children were stratified by quartile of birthweight based on sex and birth order. The approximate range of median, 25th percentile and 75th percentile of birthweight in each group was 3000-3100 g, 2700-2900 g, and 3200-3400 g, respectively (Table 1$)$.

There were 1015 (51.9\%) boys and 826 (42.3\%) first born children. In total, 128 (6.6\%) mothers smoked during pregnancy. The mean maternal age was 28.9 years (SD: 4.3 ). The mean maternal prepregnancy BMI was $20.7 \mathrm{~kg} / \mathrm{m}^{2}$ (SD: 2.8 ), and the mean birthweight of the infants was $3061 \mathrm{~g}$ (SD:

Table 1. Quartile of birthweight (g) stratified by sex of children and parity, Project Koshu, Japan, 1991-2003 $(\mathrm{N}=1955)$

\begin{tabular}{lcc|c|c}
\hline Ser and parity & Quartile 1 & Quartile 2 & Quartile 3 & Quartile 1 \\
\hline Male and first children & $<2794$ & $2794-3004$ & $3004-3240$ & $\geq 3240$ \\
Female and first children & $<2764$ & $2764-2997$ & $2997-3229$ & $\geq 3229$ \\
Male and second or more children & $<2860$ & $2860-3105$ & $3105-3382$ & $\geq 3382$ \\
Female and second or more children & $<2802$ & $2802-3050$ & $3050-3310$ & $\geq 3310$
\end{tabular}


392.7). The smoking rate was highest in the first quartile $(9.5 \%)$. The pre-pregnancy maternal BMI was the highest in the fourth quartile, and gestational age at delivery was the longest (Table 2).

Multilevel analyses showed that in the first quartile, maternal active smoking during pregnancy had a significant association with childhood BMI ( $p=0.007)$. In the same quartile, the interaction between children's age and maternal active smoking during pregnancy was significant $(\mathrm{F}=0.02)$ (Table 3$)$. In the second quartile, maternal active smoking during pregnancy had a marginally significant association with childhood BMI ( $p=0.099)$. In the same quartile, the interaction between children's age and maternal active smoking during pregnancy was significant $(\mathrm{F}=0.002)($ Table 3$)$.

Table 2. Characteristics of participants in each quartile, Project Koshu, Japan, 1991-2003 (N=1955)

\begin{tabular}{|c|c|c|c|c|}
\hline Characteristics & $\begin{array}{l}\text { Quartile } 1 \\
(n-187)\end{array}$ & $\begin{array}{c}\text { Quartile } 2 \\
(\text { (n- } 185)\end{array}$ & $\begin{array}{c}\text { Quartile } 3 \\
(\text { (n-188) }\end{array}$ & $\begin{array}{c}\text { Quartile } 4 \\
(n-195)\end{array}$ \\
\hline Male children & $252(51.8)$ & $253(52.2)$ & $253(51.8)$ & $257(51.9)$ \\
\hline First children & $206(42.3)$ & $205(42.3)$ & $206(42.2)$ & $209(42.2)$ \\
\hline Smoking mother & $46(9.5)$ & $38(7.8)$ & $25(5.1)$ & $19(3.8)$ \\
\hline Maternal age (years) & $28.8 \pm 4.2$ & $28.7 \pm 4.2$ & $28.7 \pm 4.2$ & $29.4 \pm 4.7$ \\
\hline Maternal BMI before pregnancy & $20.5 \pm 3.0$ & $20.5 \pm 2.7$ & $20.6 \pm 2.7$ & $21.4 \pm 2.9$ \\
\hline Birth order & $1.8 \pm 0.8$ & $1.8 \pm 0.8$ & $1.8 \pm 0.8$ & $1.9 \pm 0.8$ \\
\hline Gestational weeks at delivery & $38.0 \pm 1.6$ & $39.0 \pm 1.2$ & $39.3 \pm 1.1$ & $39.6 \pm 1.1$ \\
\hline Birthweight (g) & $2579.5 \pm 234.5$ & $2938.7 \pm 79.1$ & $3169.4 \pm 95.6$ & $3546.3 \pm 223.3$ \\
\hline \multicolumn{5}{|l|}{ BMI at different ages } \\
\hline At birth & $11.7 \pm 0.9$ & $12.4 \pm 0.8$ & $13.0 \pm 0.8$ & $13.8 \pm 1.0$ \\
\hline 3 years & $15.4 \pm 1.3$ & $15.8 \pm 1.3$ & $15.9 \pm 1.2$ & $16.0 \pm 1.3$ \\
\hline 5 & $15.3 \pm 1.6$ & $15.5 \pm 1.6$ & $15.6 \pm 1.4$ & $15.8 \pm 1.5$ \\
\hline $7-8$ & $15.9 \pm 2.3$ & $16.0 \pm 2.3$ & $16.1 \pm 1.9$ & $16.3 \pm 2.2$ \\
\hline $9-10$ & $17.0 \pm 3.1$ & $17.2 \pm 3.1$ & $17.1 \pm 3.1$ & $17.4 \pm 3.1$ \\
\hline
\end{tabular}

Data given as $\mathrm{n}(\%)$ or mean \pm standard deviation (SD). BMI: body mass index $\left(\mathrm{kg} / \mathrm{m}^{2}\right)$.

Table 3. Fixed effects about body mass index (BMI) $\mathrm{z}$-score in each age of children, smoking status of their mother, and interaction between each age and smoking status of their mother, Project Koshu, Japan, 1991-2003 $(\mathrm{N}=1955)$

\begin{tabular}{|c|c|c|c|c|c|c|c|c|}
\hline \multirow[t]{2}{*}{ Factor } & \multicolumn{2}{|c|}{ Quartile 1} & \multirow[b]{2}{*}{$t$} & \multirow[b]{2}{*}{ p } & \multicolumn{2}{|c|}{ Quartile 2} & \multirow[b]{2}{*}{$t$} & \multirow[b]{2}{*}{ p } \\
\hline & $\mathbf{E}$ & SE & & & E & SE & & \\
\hline Intercept & -2.61 & 0.25 & -10.59 & $<0.0001$ & -1.46 & 0.23 & -6.34 & $<0.0001$ \\
\hline Childhood age & \multicolumn{4}{|c|}{$(F<0.0001)$} & & \multicolumn{3}{|c|}{$(\mathrm{F}<0.0001)$} \\
\hline 3 years & 1.66 & 0.22 & 7.73 & $<0.0001$ & 1.58 & 0.20 & 8.09 & $<0.0001$ \\
\hline 5 & 2.03 & 0.22 & 9.37 & $<0.0001$ & 1.67 & 0.21 & 8.07 & $<0.0001$ \\
\hline $7-8$ & 1.94 & 0.25 & 7.87 & $<0.0001$ & 1.50 & 0.23 & 6.49 & $<0.0001$ \\
\hline $9-10$ & 2.24 & 0.25 & 8.87 & $<0.0001$ & 1.42 & 0.25 & 5.64 & $<0.0001$ \\
\hline Maternal smoking during pregnancy & 0.37 & 0.14 & 2.72 & 0.007 & 0.19 & 0.11 & 1.65 & 0.10 \\
\hline Childhood age $^{*}$ & \multicolumn{4}{|c|}{$(F=0.02)$} & \multicolumn{4}{|c|}{$(\mathrm{F}=0.002)$} \\
\hline 3 years & -0.33 & 0.22 & -1.48 & 0.14 & -0.69 & 0.20 & -3.39 & 0.0008 \\
\hline 5 & -0.64 & 0.23 & -2.82 & 0.005 & -0.80 & 0.22 & -3.74 & 0.0002 \\
\hline $7-8$ & -0.48 & 0.26 & -1.86 & 0.06 & -0.65 & 0.24 & -2.71 & 0.007 \\
\hline $9-10$ & -0.68 & 0.26 & -2.56 & 0.01 & -0.44 & 0.26 & -1.68 & 0.09 \\
\hline Maternal BMI before pregnancy & 0.038 & 0.0102 & 3.69 & 0.0002 & 0.0243 & 0.0095 & 2.57 & 0.01 \\
\hline
\end{tabular}


Table 3. Continued

\begin{tabular}{|c|c|c|c|c|c|c|c|c|}
\hline \multirow[t]{2}{*}{ Factor } & \multicolumn{2}{|c|}{ Quartile 3} & \multirow[b]{2}{*}{$t$} & \multirow[b]{2}{*}{ p } & \multicolumn{2}{|c|}{ Quartile 1} & \multirow[b]{2}{*}{$t$} & \multirow[b]{2}{*}{$p$} \\
\hline & E & SE & & & E & SE & & \\
\hline Intercept & -0.91 & 0.24 & -3.77 & 0.0002 & -0.93 & 0.25 & -3.71 & 0.0002 \\
\hline Childhood age & & & $(F<0.0001)$ & & & $(F=0.83)$ & & \\
\hline 3 years & 0.67 & 0.22 & 3 & 0.003 & 0.33 & 0.30 & 1.13 & 0.26 \\
\hline 5 & 0.81 & 0.23 & 3.5 & 0.0005 & 0.41 & 0.31 & 1.35 & 0.18 \\
\hline $7-8$ & 0.82 & 0.26 & 3.17 & 0.0016 & 0.50 & 0.37 & 1.33 & 0.18 \\
\hline $9-10$ & 0.86 & 0.27 & 3.24 & 0.001 & 0.35 & 0.40 & 0.87 & 0.39 \\
\hline Maternal smoking during pregnancy & 0.10 & 0.14 & 0.71 & 0.48 & 0.108 & 0.17 & 0.64 & 0.52 \\
\hline Childhood age ${ }^{*}$ & & & $(F=0.44)$ & & & & $\mathrm{F}=0.61)$ & \\
\hline 3 years & -0.11 & 0.23 & -0.47 & 0.64 & -0.39 & 0.30 & -1.29 & 0.20 \\
\hline 5 & -0.35 & 0.24 & -1.47 & 0.14 & -0.46 & 0.31 & -1.48 & 0.14 \\
\hline $7-8$ & -0.36 & 0.27 & -1.36 & 0.17 & -0.59 & 0.38 & -1.56 & 0.12 \\
\hline $9-10$ & -0.34 & 0.27 & -1.23 & 0.22 & -0.41 & 0.41 & -1.00 & 0.32 \\
\hline Maternal BMI before pregnancy & 0.023 & 0.0095 & 2.43 & 0.02 & 0.055 & 0.0094 & 5.84 & $<0.0001$ \\
\hline
\end{tabular}

BMI: body mass index $\left(\mathrm{kg} / \mathrm{m}^{2}\right)$. ${ }^{*}$ Children of mothers smoking during pregnancy. E: estimate. SE: standard error.

In every quartile, although children born to those born to non-smoking mothers. The difference smoking mothers were leaner at birth, their BMI in birthweight trajectory between children born to z-scores increased rapidly by the age of 3 years (the smoking and non-smoking mothers was larger in the 2nd and 4th quartiles); after the age of 3 years (the first and second quartiles than in the other groups 1 st and 3rd quartiles), these children were larger than (Figure 1).

Figure 1. Body mass index (BMI) z-score trajectories of children between smoking and non-smoking mothers in each quartile of birthweight calculated by individual growth analysis, Project Koshu, Japan, 1991-2003 (N=1955)

Birth weight: Quartile 1

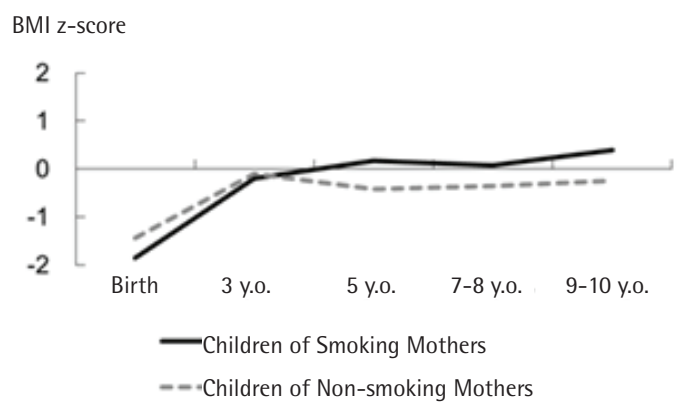

Birth weight: Quartile 3

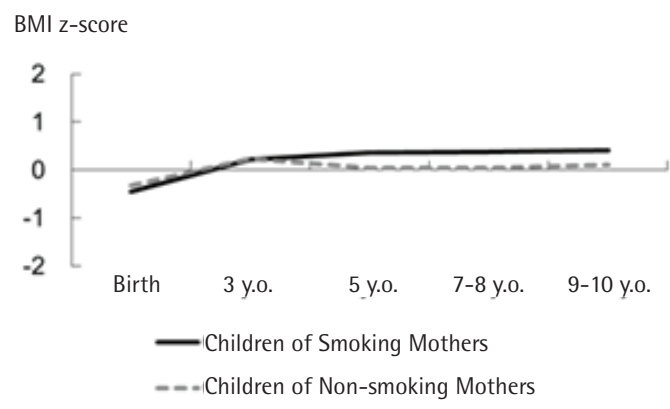

Birth weight: Quartile 2

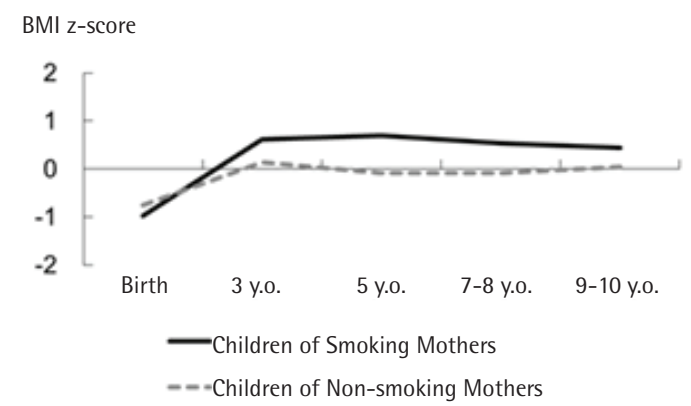

Birth weight: Quartile 4

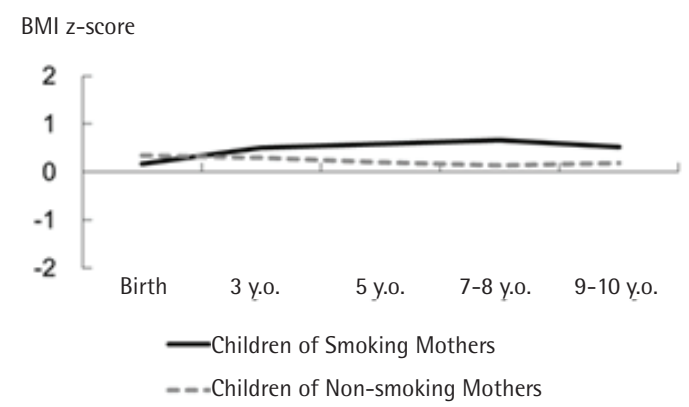




\section{DISCUSSION}

The present study examined differences in the effect of maternal active smoking during pregnancy on childhood growth based on trajectories of childhood BMI z-scores using multilevel model analyses stratified by quartile of birthweight. Regardless of sex and parity, the largest difference in the effect of maternal smoking on childhood BMI was observed when the birthweight was lower than the median value. In addition, rapid growth during infancy, which could be associated with subsequent obesity ${ }^{25-27}$, was observed in the second quartile of birthweight. Therefore, in the second quartile of birthweight, maternal active smoking during pregnancy might contribute to an increase in childhood BMI.

Many factors, including maternal active smoking during pregnancy, sex of the child, parity, gestational age, maternal age, pregestational maternal weight, gestational weight gain, hypertensive disorders during pregnancy, and gestational diabetes, have been associated with the birthweight of the infant ${ }^{30-36}$. Thus, to examine the association between maternal active smoking during pregnancy and birthweight, it is necessary to consider these factors as confounders or effect modifiers. Since the subjects were stratified based on sex and parity within the birthweight quartiles in this study, the effect of these factors might be limited. In addition, because Japanese vital statistics showed that maternal age might be associated with parity ${ }^{37}$, the effect of maternal age on birthweight might be partially controlled. However, the effect of other factors, including potential confounding factors, was not considered in the present study and might have impacted our results. Since Hernández-Diaz et al. ${ }^{7}$ evaluated the effect of these potential factors on birthweight and infant mortality using DAGs, our results could be interpreted by similar methods.

Our previous study on the effect of maternal active smoking during pregnancy on birthweight, which adjusted for clinical, socioeconomic, and maternal lifestyle factors, showed that maternal active smoking during pregnancy might reduce the birthweight by $120-150 \mathrm{~g}$ and approximately $130 \mathrm{~g}$ in this study area and nationwide, respectively ${ }^{19,20}$. Therefore, similar to the findings in the report by HernandezDiaz et al. ${ }^{7}$, which demonstrated that maternal active smoking during pregnancy shifted the distribution of infant mortality, smoking also shifts the distribution of birthweight to a lower weight. However, since the birthweight in the first quartile and mean birthweight in Japan were $<2800 \mathrm{~g}$ and approximately $3000 \mathrm{~g}$, respectively, factors other than maternal active smoking during pregnancy might have reduced the birthweight in the first-quartile group.

In addition to birthweight, factors like short gestational age also reduced the BMI in early childhood $^{38-40}$. Infants in the first quartile might have a reduced birthweight due to maternal active smoking during pregnancy and other factors like gestational age. In view of these findings, the impact of maternal active smoking during pregnancy on childhood BMI might be underestimated in infants with relatively low birthweight.

In contrast, birthweights in the third and fourth quartiles were higher than the median regardless of maternal active smoking during pregnancy, implying the effect of opposing factors that increase birthweight, like appropriate gestational weight gain. The concept of DOHaD suggests that mismatched foetal and early infant environments might adversely affect future health status ${ }^{41}$. Therefore, in these quartiles, appropriate foetal factors that increase birthweight might reduce the adverse effects of maternal active smoking during pregnancy on childhood BMI.

Our results suggest that when determining the effect of maternal active smoking on foetal and childhood BMI, it is necessary to consider factors other than maternal active smoking during pregnancy as both confounding and effect modification factors.

\section{Strengths and limitations}

This study has certain limitations. First, as it was conducted in only one rural Japanese area, the results might not be generalizable. However, in previous studies, the effect of maternal active smoking during pregnancy on birthweight in this area was similar to that observed nationwide. Additionally, the validity of the maternal smoking status might have been low as this information was obtained using a questionnaire. However, the effect of differential misclassification, which occurs when participants are unwilling to admit smoking, might be small. Finally, the period effects due to the long study period could have influenced the results. This study also has several strengths. First, although the follow-up period was relatively long, the follow-up rate was almost $80 \%$ for each age group. 
Thus, selection bias might be minimal. In addition, because the number of participants was large, the statistical power might be relatively high, although stratified analyses were conducted.

\section{CONCLUSIONS}

The effect of maternal active smoking during pregnancy on childhood growth was more apparent among children in the second quartile of birthweight; rapid growth in infancy was also observed in children of smoking mothers in this group. It is necessary to consider other potential factors that modify the effect of maternal smoking during pregnancy on childhood BMI.

\section{REFERENCES}

1. Swanson JM, Entringer S, Buss C, Wadhwa PD. Developmental origins of health and disease: environmental exposures. Semin Reprod Med. 2009;27(5):391-402. doi:10.1055/s-0029-1237427

2. Phillips DI. Insulin resistance as a programmed response to fetal undernutrition. Diabetologia. 1996;39(9):11191122. doi:10.1007/bf00400663

3. Eriksson JG, Forsén T, Tuomilehto J, Osmond C, Barker DJ. Early adiposity rebound in childhood and risk of Type 2 diabetes in adult life. Diabetologia. 2003;46(2):190194. doi:10.1007/s00125-002-1012-5

4. Bhargava SK, Sachdev HS, Fall CH, et al. Relation of serial changes in childhood body-mass index to impaired glucose tolerance in young adulthood. N Engl J Med. 2004;350(9):865-875. doi:10.1056/nejmoa035698

5. Barker DJ, Osmond C, Forsén TJ, Kajantie E, Eriksson JG. Trajectories of growth among children who have coronary events as adults. N Engl J Med. 2005;353(17):18021809. doi:10.1056/nejmoa044160

6. Wilcox AJ. On the importance-and the unimportanceof birthweight. Int J Epidemiol. 2001;30(6):1233-1241. doi:10.1093/ije/30.6.1233

7. Hernandez-Diaz S, Schisterman EF, Hernan, MA. The birth weight 'paradox' uncovered? Am J Epidemiol. 2002;164(11):1115-1120. doi:10.1093/aje/kwj275

8. Conter V, Cortinovis I, Rogari P, Riva L. Weight growth in infants born to mothers who smoked during pregnancy. BMJ. 1995;310(6982):768-771. doi:10.1136/bmj.310.6982.768

9. Chiolero A, Bovet P, Paccaud F. Association between maternal smoking and low birth weight in Switzerland: the EDEN study. Swiss Med Wkly. 2005;135(35-36):525530. doi:2005/35/smw-11122

10. Heaman M, Kingston D, Chalmers B, Sauve R, Lee L, Young D. Risk factors for preterm birth and small-for-gestationalage births among Canadian women. Paediatr Perinat Epidemiol. 2013;27(1):54-61. doi:10.1111/ppe.12016

11. Reeves S, Bernstein I. Effects of maternal tobacco- smoke exposure on fetal growth and neonatal size. Expert Rev Obstet Gynecol. 2008;3(6):719-730. doi:10.1586/17474108.3.6.719

12. Power C, Jefferis BJ. Fetal environment and subsequent obesity: a study of maternal smoking. Int J Epidemiol. 2002;31(2):413-419. doi:10.1093/ije/31.2.413

13. Toschke AM, Koletzko B, Slikker W Jr, Hermann M, von Kries R. Childhood obesity is associated with maternal smoking in pregnancy. Eur J Pediatr. 2002;161(8):445448. doi:10.1007/s00431-002-0983-z

14. von Kries R, Toschke AM, Koletzko B, Slikker W Jr. Maternal smoking during pregnancy and childhood obesity. Am J Epidemiol. 2002;156(10):954-961. doi:10.1093/aje/kwf128

15. Toschke AM, Montgomery SM, Pfeiffer U, von Kries R. Early intrauterine exposure to tobacco-inhaled products and obesity. Am J Epidemiol. 2003;158(11):1068-1074. doi:10.1093/aje/kwg258

16. Vik T, Jacobsen G, Vatten L, Bakketeig LS. Pre- and post-natal growth in children of women who smoked in pregnancy. Early Hum Dev. 1996;45(3):245-255. doi:10.1016/0378-3782(96)01735-5

17. Widerøe M, Vik T, Jacobsen G, Bakketeig LS. Does maternal smoking during pregnancy cause childhood overweight? Paediatr Perinat Epidemiol. 2003;17(2):171179. doi:10.1046/j.1365-3016.2003.00481.x

18. Suzuki K, Tanaka T, Kondo N, Minai J, Sato M, Yamagata Z. Is maternal smoking during early pregnancy a risk factor for all low birth weight infants? J Epidemiol. 2008;18(3):89-96. doi:10.2188/jea.je2007415

19. Suzuki K, Sato M, Zheng W, Shinohara R, Yokomichi $\mathrm{H}$, Yamagata Z. Effect of maternal smoking cessation before and during early pregnancy on fetal and childhood growth. J Epidemiol. 2014;24(1):60-66. doi:10.2188/jea.je20130083

20. Suzuki K, Shinohara R, Sato M, Otawa S, Yamagata Z. Association between maternal smoking during pregnancy and birth weight: an appropriately adjusted model from the Japan Environment and Children's Study. J Epidemiol. 2016;26(7):371-377. doi:10.2188/jea.je20150185

21. Mizutani T, Suzuki K, Kondo N, Yamagata Z. Association of maternal lifestyles including smoking during pregnancy with childhood obesity. Obesity (Silver Spring). 2007;15(12):3133-3139. doi:10.1038/oby.2007.373

22. Suzuki K, Ando D, Sato M, et al. The association between maternal smoking during pregnancy and childhood obesity persists to the age of 9-10 years. J Epidemiol. 2008;19(3):136-142. doi:10.2188/jea.je20081012

23. Suzuki K, Kondo N, Sato M, Tanaka T, Ando D, Yamagata Z. Gender differences in the association between maternal smoking during pregnancy and childhood growth trajectories: multilevel analysis. Int J Obes. 2011;35(1):53-59. doi:10.1038/ijo.2010.198

24. Zheng W, Suzuki K, Shinohara R, Sato M, Yokomichi 
H, Yamagata Z. Maternal smoking during pregnancy and growth in infancy: a covariance structure analysis. J Epidemiol. 2015;25(1):44-49. doi:10.2188/jea.je20140040

25. Ong KK, Loos RJ. Rapid infancy weight gain and subsequent obesity: systematic reviews and hopeful suggestions. Acta Paediatr. 2006;95(8):904-908. doi:10.1080/08035250600719754

26. Monteiro PO, Victora GG. Rapid growth in infancy and childhood and obesity in later life-a systematic review. Obes Rev. 2005;6(2):143-154. doi:10.1111/j.1467-789x.2005.00183.x

27. Druet C, Stettler N, Sharp S, et al. Prediction of childhood obesity by infancy weight gain: an individual-level metaanalysis. Paediatr Perinat Epidemiol. 2012;26(1):19-26. doi:10.1111/j.1365-3016.2011.01213.x

28. World Health Organization. WHO Child Growth Standards: Methods and development: Length/heightfor-age, weight-for-age, weight-for-length, weight-forheight and body mass index-for-age. Geneva, Switzerland: World Health Organization; 2006. https://www.who. int/childgrowth/standards/Technical_report.pdf?ua $=1$. Accessed January 19, 2020.

29. Fitzmaurice GM, Laird NM, Ware JH. Applied Longitudinal Analysis. New Jersey, NJ: Wiley-Interscience; 2004.

30. Minakami H, Maeda T, Fujii T, et al. Guidelines for obstetrical practice in Japan: Japan Society of Obstetrics and Gynecology (JSOG) and Japan Association of Obstetricians and Gynecologists (JAOG) 2014 edition. J Obstet Gynaecol Res. 2014;40(6):1469-1499. doi:10.1111/jog.12419

31. Chiavaroli V, Castorani V, Guidone P, et al. Incidence of infants born small- and large-for-gestationalage in an Italian cohort over a 20-year period and associated risk factors. Ital J Pediatr. 2016;42(1):42. doi:10.1186/s13052-016-0254-7

32. León G, Murcia M, Rebagliato M, et al. Maternal thyroid dysfunction during gestation, preterm delivery, and birthweight. The Infancia y Medio Ambiente Cohort, Spain. Paediatr Perinat Epidemiol. 2015;29(2):113-122. doi:10.1111/ppe.12172

33. Hinkle SN, Albert PS, Mendola P, et al. Differences in risk factors for incident and recurrent small-for-gestationalage birthweight: a hospital-based cohort study. BJOG. 2014;121(9):1080-1088. doi:10.1111/1471-0528.12628

34. Yeniel AO, Ergenoglu AM, Itil IM, Askar N, Meseri R. Effect of placenta previa on fetal growth restriction and stillbirth. Arch Gynecol Obstet. 2012;286(2):295-298. doi:10.1007/s00404-012-2296-4

35. Terada M, Matsuda Y, Ogawa M, Matsui H, Satoh S. Effects of factors on birth weight in Japan. J Pregnancy. 2013;2013:172395. doi:10.1155/2013/172395

36. Rao J, Fan D, Wu S, et al. Trend and risk factors of low birth weight and macrosomia in south China, 20052017: a retrospective observational study. Sci Rep. 2018;8(1):3393. doi:10.1038/s41598-018-21771-6
37. Vital, Health and Social Statistics Division, Statistics and Information Department, Minister's Secretariat, Ministry of Health, Labour and Welfare. [Vital Statistics of Japan]. https://www.mhlw.go.jp/toukei/saikin/hw/jinkou/ suii09/brth5.html. Accessed September 8, 2019.

38. Gupta P, Mital R, Kumar B, Yadav A, Jain M, Upadhyay A. Physical growth, morbidity profile and mortality among healthy late preterm neonates. Indian Pediatr. 2017;54(8):629-634. doi:10.1007/s13312-017-1123-1

39. Satos IS, Matijasevich A, Domingues MR, Barros AJ, Voctora CG, Barros FC. Late preterm birth is a risk factor for growth faltering in early childhood: a cohort study. BMC Pediatr. 2009;9(1):71. doi:10.1186/1471-2431-9-71

40. Goyal NK, Fiks AG, Lorch SA. Persistence of underweight status among late preterm infants. Arch Pediatr Adolesc Med. 2012;166(5):424-430. doi:10.1001/archpediatrics.2011.1496

41. Kikuchi T, Uchiyama M. Epidemiological studies of the developmental origins of adult health and disease in Japan: a pediatric perspective in present day Japan. Clin Pediatr Endocrinol. 2010;19(4):83-90. doi:10.1297/cpe.19.83

\section{ACKNOWLEDGEMENTS}

The study was conducted by members of Project Koshu, including Ryoji Shinohara, Hiroshi Yokomichi, Miri Sato, Sonoko Mizorogi, Yuka Akiyama, Reiji Kojima, Tadao Ooka, and the Administrative Office staff of Koshu City. We thank the study participants for providing their personal data.

\section{CONFLICTS OF INTEREST}

The authors have completed and submitted the ICMJE Form for Disclosure of Potential Conflicts of Interest and none was reported.

\section{FUNDING}

This work was supported by Grants-in-Aid for Scientific Research (KAKENHI 23390173, 20590639, 23590785, 15K08731 and 18K10076) from the Ministry of Education, Culture, Sports, Science and Technology (MEXT), Japan and Health Labour Sciences Research Grants (19DA1003) from The Ministry of Health, Labour, and Welfare.

\section{AUTHORS' CONTRIBUTIONS}

$\mathrm{KS}$ and $\mathrm{ZY}$ conceived and designed the study. $\mathrm{KS}$ and $\mathrm{ZY}$ obtained funding and provided administrative support. ZY coordinated all logistics and closely supervised the study. KS and ZY were involved in data collection and organization, as well as performing statistical analyses. MK and KS drafted the first version of the manuscript. KS was principally involved in advising and revising the manuscript. ZY revised and edited the manuscript. All the authors read and approved the final manuscript.

\section{PROVENANCE AND PEER REVIEW}

Not commissioned; externally peer reviewed. 